Supporting Information

\title{
Tunable Interpenetrating Polymer Network Hydrogels based on Dynamic Covalent Bonds and Metal-Ligand Bonds
}

Hui Yang, Sina Ghiassinejad, Evelyne Van Ruymbeke*, Charles-André Fustin*

Institute of Condensed Matter and Nanosciences (IMCN), Bio and Soft Matter Division (BSMA), Université catholique de Louvain, Place L. Pasteur 1 \& Croix du Sud 1, B-1348 Louvain-la-Neuve, Belgium

*E-mail: charles-andre.fustin@uclouvain.be

*E-mail: evelyne.vanruymbeke@uclouvain.be

\section{Table of Contents}

1. Experimental Section

2. Supplementary Figures

3. References 


\section{Experimental Section}

\subsection{Reagents and Materials}

Unless otherwise stated, all the reagents were purchased at the highest purity available and used without further purification. The organic solvents used for synthesis were purified by conventional methods. $^{[1]}$ 4-Chloro-2,2':6',2"'-terpyridine was purchased from Acros Organics Co. 2-(2Aminoethoxy) ethanol and succinic dihydrazide were purchased from TCI Tokyo Chemical Industry Co. Aluminum oxide (activated, basic, Brockmann Grade I, 58 angstroms) was from Alfa Aesar Co. Acryloyl chloride and O,O'-(propane-1,3-diyl)bis(hydroxylamine) dihydrochloride were from Sigma Aldrich Co. N,N-Dimethylacrylamide (DMA) was from Sigma Aldrich Co., Ltd. and was passed through basic alumina immediately prior to use. Diacetone acrylamide (DAAM) was from Alfa Aesar Co. and was recrystallized three times in dichloromethane/ $n$-hexane (1/4). 2,2'-Azobis(isobutyronitrile) (AIBN) was recrystallized two times in methanol. S-1-dodecyl-S'$(\alpha, \alpha$ '-dimethyl- $\alpha$ "-acetic acid)trithiocarbonate (DDMAT) was synthesized following a reported procedure $^{[2]}$ and recrystallized two times in $n$-hexane.

\subsection{Preparation and Characterization of Monomers}

\subsubsection{Synthesis of 2-(2-([2,2':6',2''-terpyridine $]-4^{\prime}-$ yloxy)ethoxy)ethan-1-amine (TPy-DEG-} $\mathrm{NH}_{2}$ )<smiles>NCCOCCO</smiles><smiles></smiles>

Scheme S1. Synthetic route of TPy-DEG-NH2. 
The TPy-DEG-NH $\mathrm{N}_{2}$ was synthesized following a literature method. ${ }^{[3]}$ 2-(2-aminoethoxy)ethanol (216 mg, $2.05 \mathrm{mmol}$ ) and anhydrous $\mathrm{KOH}(735 \mathrm{mg}, 13.1 \mathrm{mmol})$ were dispersed in $7 \mathrm{~mL}$ of dry DMSO. The suspension was stirred at $60^{\circ} \mathrm{C}$ for $1 \mathrm{~h}$ under argon atmosphere. To this mixture, 4chloro-2,2':6',2' '-terpyridine (500 $\mathrm{mg}, 1.87 \mathrm{mmol}$ ) was subsequently added, and the reaction mixture was heated at $70{ }^{\circ} \mathrm{C}$ for an additional $24 \mathrm{~h}$. The reaction mixture was then placed under reduced pressure at $60{ }^{\circ} \mathrm{C}$ to remove most of DMSO. The residue was allowed to cool down to room temperature, and $80 \mathrm{~mL}$ of deionized water were added and stirred for $3 \mathrm{~h}$. This aqueous solution was extracted with DCM $(3 \times 50 \mathrm{~mL})$. The organic phases were collected and dried with anhydrous $\mathrm{Na}_{2} \mathrm{SO}_{4}$, and then concentrated under vacuum to get a yellow solid with $74 \%$ yield (0.465 g). ${ }^{1} \mathrm{H}$ NMR (300 MHz, $\mathrm{CDCl}_{3}, \delta$ ): 8.66 (dd, $\left.2 \mathrm{H}, \mathrm{CH}_{\text {terpy }}, \mathrm{H}_{6,6}{ }^{\prime}\right), 8.58$ (d, $2 \mathrm{H}, \mathrm{CH}_{\text {terpy }}, \mathrm{H}_{3}$, 3"), 8.04 (s, 2H, $\left.\mathrm{CH}_{\text {terpy }}, \mathrm{H}_{3^{\prime}}, 5^{\prime}\right), 7.83$ (td, $2 \mathrm{H}, \mathrm{CH}_{\text {terpy }}, \mathrm{H}_{4,4}$ "), 7.32 (qd, 2H, $\left.\mathrm{CH}_{\text {terpy }}, \mathrm{H}_{5,5},{ }^{\prime \prime}\right), 4.38$ (t, $2 \mathrm{H}, \mathrm{CH}_{2}, \mathrm{H}_{\mathrm{a}}$ ), 3.89 (t, 2H, $\mathrm{CH}_{2}, \mathrm{H}_{\mathrm{d}}$ ), 3.59 (t, 2H, $\mathrm{CH}_{2}, \mathrm{H}_{\mathrm{b}}$ ), 2.88 (t, 2H, $\mathrm{CH}_{2}, \mathrm{H}_{\mathrm{c}}$ ), 1.77 (s, broad, $\left.\mathrm{NH}_{2}\right)$. ESI-MS: $\left([\mathrm{M}+\mathrm{H}]^{+}\right)=337.1659 \mathrm{~g} / \mathrm{mol}$.

\subsubsection{Synthesis of $N-\left(2-\left(2-\left(\left[2,2^{\prime}: 6^{\prime}, 2^{\prime \prime}\right.\right.\right.\right.$-terpyridine $]-4^{\prime}$-yloxy)ethoxy)ethyl)acrylamide (TPy- DEG-AM)}
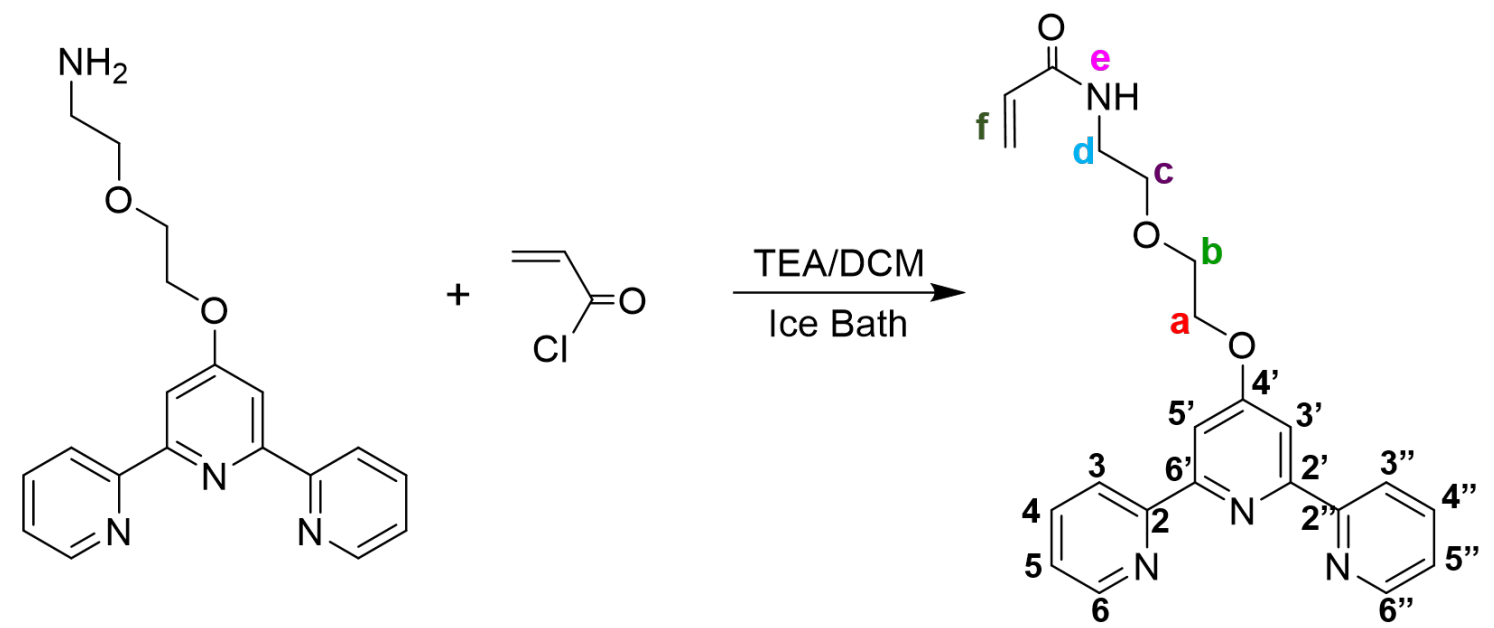

Scheme S2. Synthetic route of TPy-DEG-AM.

TPy-DEG-NH $2(0.20 \mathrm{~g}, 0.60 \mathrm{mmol})$ and dry triethylamine $(0.12 \mathrm{~g}, 1.2 \mathrm{mmol})$ were dissolved in dry DCM $(10 \mathrm{~mL})$ on an ice bath under argon atmosphere. To this solution, a solution of acryloyl chloride $(0.11 \mathrm{~g}, 1.2 \mathrm{mmol})$ in $5 \mathrm{~mL}$ of dry DCM was added dropwise under stirring. After the addition was completed, the reaction mixture was stirred overnight at room temperature, and then quenched with $15 \mathrm{~mL}$ of a saturated solution of $\mathrm{Na}_{2} \mathrm{CO}_{3}$. The organic fraction was isolated, and 
the aqueous fraction was extracted with dichloromethane $(3 \times 15 \mathrm{~mL})$. The organic phases were recombined and dried with anhydrous $\mathrm{Na}_{2} \mathrm{CO}_{3}$, and then concentrated under vacuum below $25^{\circ} \mathrm{C}$. The crude product was purified through column chromatography (basic aluminum oxide), eluting with a mixture of ethyl acetate / hexane (gradient from $14 \%$ to $80 \%$ of ethyl acetate). The pure N(2-(2-([2,2':6',2"-terpyridin]-4'-yloxy)ethoxy)ethyl)acrylamide (TPy-DEG-AM) was obtained as a white solid with $77 \%$ yield $(0.179 \mathrm{~g}) .{ }^{1} \mathrm{H}$ NMR $\left(300 \mathrm{MHz}, \mathrm{CDCl}_{3}, \delta\right): 8.69$ (dd, $2 \mathrm{H}, \mathrm{CH}_{\text {terpy }}, \mathrm{H}_{6}$, 6"), 8.63 (d, $2 \mathrm{H}, \mathrm{CH}_{\text {terpy }}, \mathrm{H}_{3,3^{\prime \prime}}$ ), 8.10 (s, $\left.2 \mathrm{H}, \mathrm{CH}_{\text {terpy }}, \mathrm{H}_{3^{\prime}}, 5^{\prime}\right), 7.86$ (td, $2 \mathrm{H}, \mathrm{CH}_{\text {terpy }}, \mathrm{H}_{4,4^{\prime \prime}}$ ), 7.35 (qd, $2 \mathrm{H}, \mathrm{CH}_{\text {terpy }}, \mathrm{H}_{5,5}$ "), 6.46 (br, 1H; $\mathrm{CONH}$ ), 6.21 (dd, 1H, $\mathrm{CH}_{2}=\mathrm{CH}$ ), 6.01 (dd, 1H, $\mathrm{CH}_{2}=\mathrm{CH}$ ), 5.56 (dd, $1 \mathrm{H}, \mathrm{CH}_{2}=\mathrm{CH}$ ), 4.43 (m, 2H, CH $\left.2, \mathrm{H}_{\mathrm{a}}\right), 3.90$ (m, 2H, CH $\left.2, \mathrm{H}_{\mathrm{d}}\right), 3.68$ (t, 2H, $\mathrm{CH}_{2}, \mathrm{H}_{\mathrm{b}}$ ), 3.59 (t, $\left.2 \mathrm{H}, \mathrm{CH}_{2}, \mathrm{H}_{\mathrm{c}}\right)$. ESI-MS: $\left([\mathrm{M}+\mathrm{H}]^{+}\right)=391.1765 \mathrm{~g} / \mathrm{mol}$.

\subsection{Preparation and Characterization of Copolymers}

\subsubsection{Synthesis of side-chain ketone-functionalized poly(N,N-dimethylacrylamide), P(DMA- co-Ketone).}

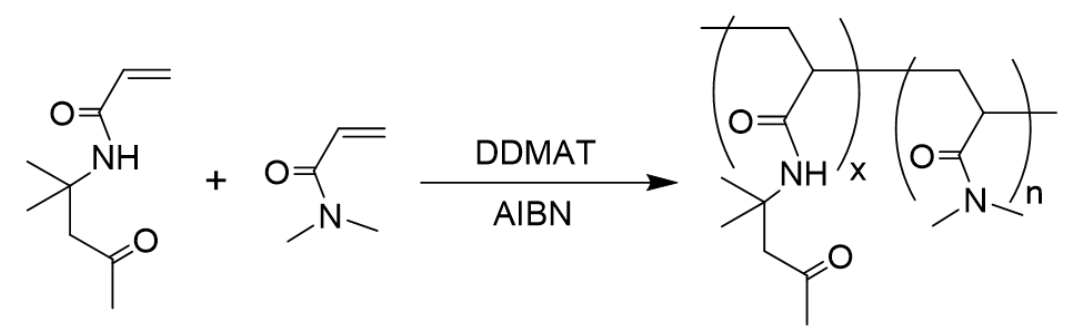

Scheme S3. Synthetic route of P(DMA-co-Ketone).

AIBN (2.5 mg, 0.015mmol), DDMAT (36.5 mg, 0.1 mmol), DAAM (389.2 mg, 2.3mmol) and DMA (5.472 g, $55.2 \mathrm{mmol}$ ) were dissolved in $10 \mathrm{~mL}$ of dry dioxane in a $50 \mathrm{~mL}$ round-bottom Schlenk-flask. The solution was degassed by five freeze-pump-thaw cycles, backfilled with argon, and stirred in a preheated oil bath at $70^{\circ} \mathrm{C}$ for $5 \mathrm{~h}$. The polymerization was stopped by opening the flask to air and placing it in liquid nitrogen. The conversion of monomer was determined to be $78 \%$, by comparing the integral ratio of the vinyl signals to the methylene proton of dioxane on the ${ }^{1} \mathrm{H}$ NMR spectrum. The viscous liquid was diluted with DCM and precipitated three times in 20 -times volume excess of diethyl ether, and the polymer was finally dried in a vacuum oven at $40{ }^{\circ} \mathrm{C}$ for $24 \mathrm{~h}$. The product was characterized by ${ }^{1} \mathrm{H}$ NMR and GPC. 


\subsubsection{Synthesis of side-chain terpyridine-functionalized poly( $\mathbf{N}, \mathbf{N}$-dimethylacrylamide), P(DMA-co-Tpy).}

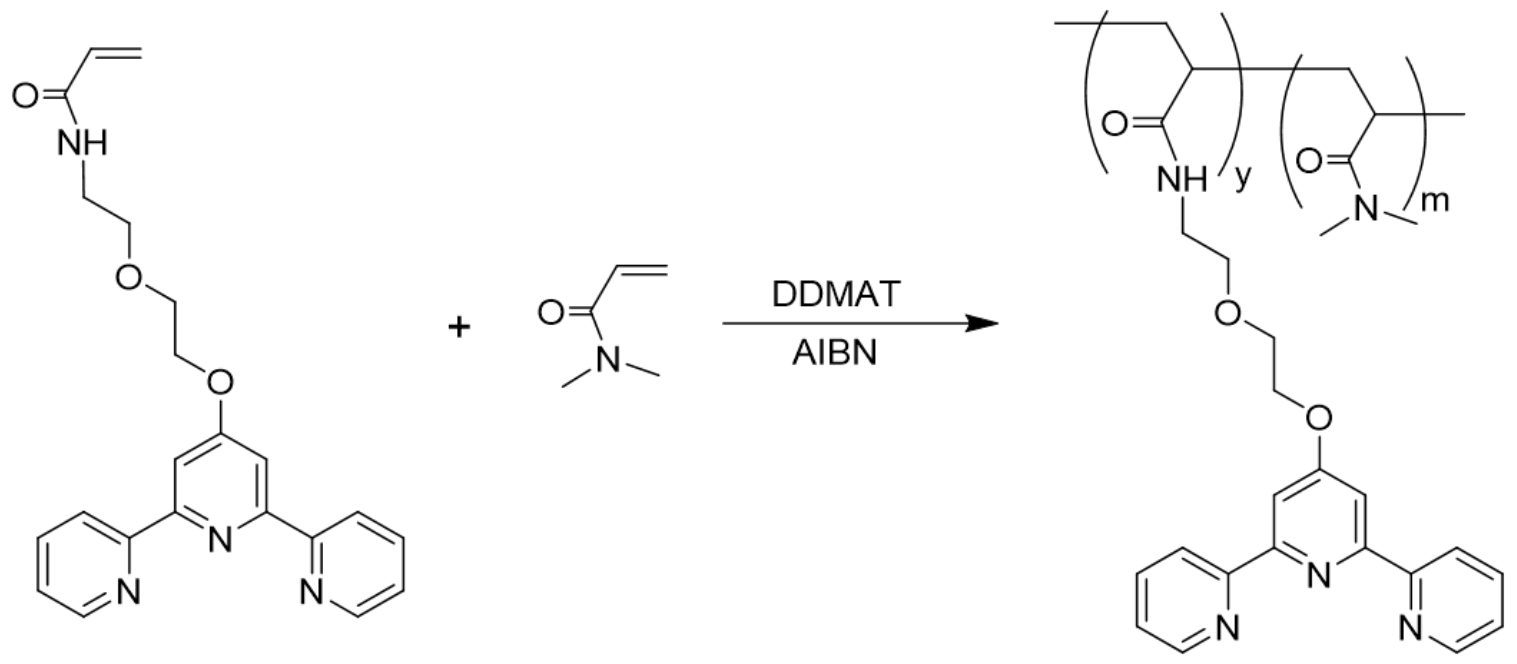

Scheme S4. Synthetic route of P(DMA-co-Tpy).

AIBN (0.62 mg, $0.00375 \mathrm{mmol})$, DDMAT (9.12 mg, $0.025 \mathrm{~mol})$, TPy-DEG-AM (113.23 mg, $0.29 \mathrm{mmol})$ and DMA $(1.397 \mathrm{~g}, 14.09 \mathrm{mmol})$ were dissolved in $4.5 \mathrm{~mL}$ of dry DMF and $0.5 \mathrm{~mL}$ of dry anisole in a $25 \mathrm{~mL}$ round-bottom Schlenk-flask. The solution was degassed by five freezepump-thaw cycles, backfilled with argon and stirred in a preheated oil bath at $70{ }^{\circ} \mathrm{C}$ for $18 \mathrm{~h}$. The polymerization was stopped by opening the flask to air and placing it in liquid nitrogen. The conversion of monomer was determined to be $86 \%$ by comparing the integral ratio of the vinyl signal to the methyl proton of anisole on the ${ }^{1} \mathrm{H}$ NMR spectrum. The viscous liquid was diluted with DCM and precipitated three times in 20-times volume excess diethyl ether, and the polymer was finally dried in a vacuum oven at $40{ }^{\circ} \mathrm{C}$ for $24 \mathrm{~h}$. The product was characterized by ${ }^{1} \mathrm{H}$ NMR and GPC.

\subsection{Preparation of Networks}

For all the prepared networks, the amount of added crosslinkers (di-hydrazides, bishydroxylamines or transition metal cations) was half an equivalent compared to the reactive sites (ketone or terpyridine groups) of the copolymers. The $d i$-hydrazide (succinic dihydrazide) or bishydroxylamine (O,O'-(propane-1,3-diyl)bis(hydroxylamine) dihydrochloride) was used to react with ketone groups of P(DMA-co-Ketone) to build dynamic Schiff base binding network, and the 
transition metal cations $\left(\mathrm{FeCl}_{2}\right.$ or $\left.\mathrm{ZnCl}_{2}\right)$ were employed to interact with terpyridine groups of $\mathrm{P}(\mathrm{DMA}-\mathrm{co}$-Tpy) to get metal-terpyridine association bridging network.

\section{Preparation of individual networks}

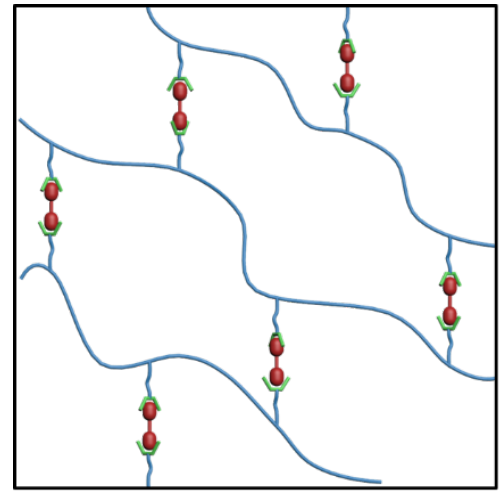

Individual oxime network

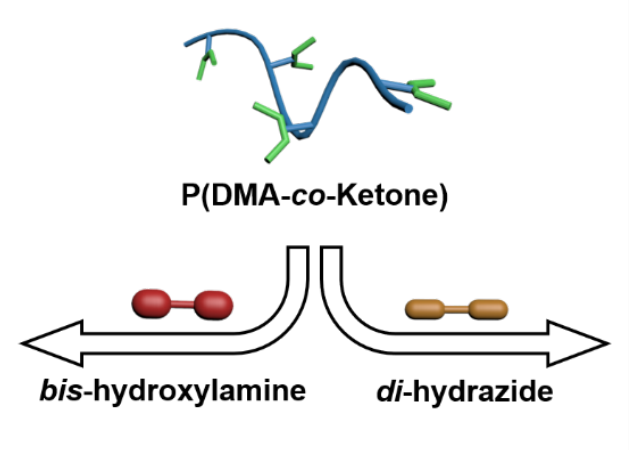

Individual acylhydrazone network

Scheme S5. Preparation of individual dynamic Schiff base bonding networks in water from P(DMA-co-Ketone) (10 wt.\%).

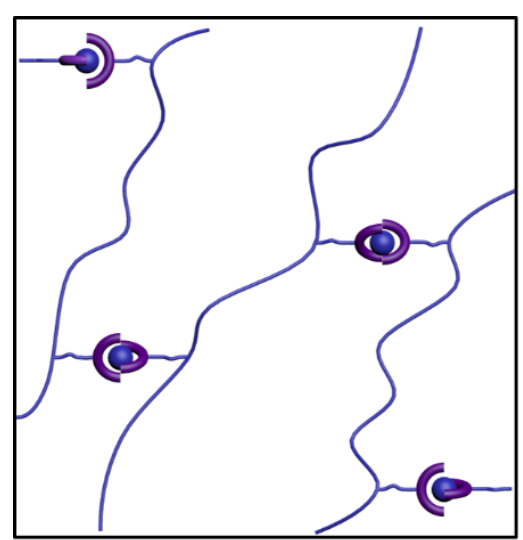

Individual $\mathrm{Fe}^{2+}$-Tpy network

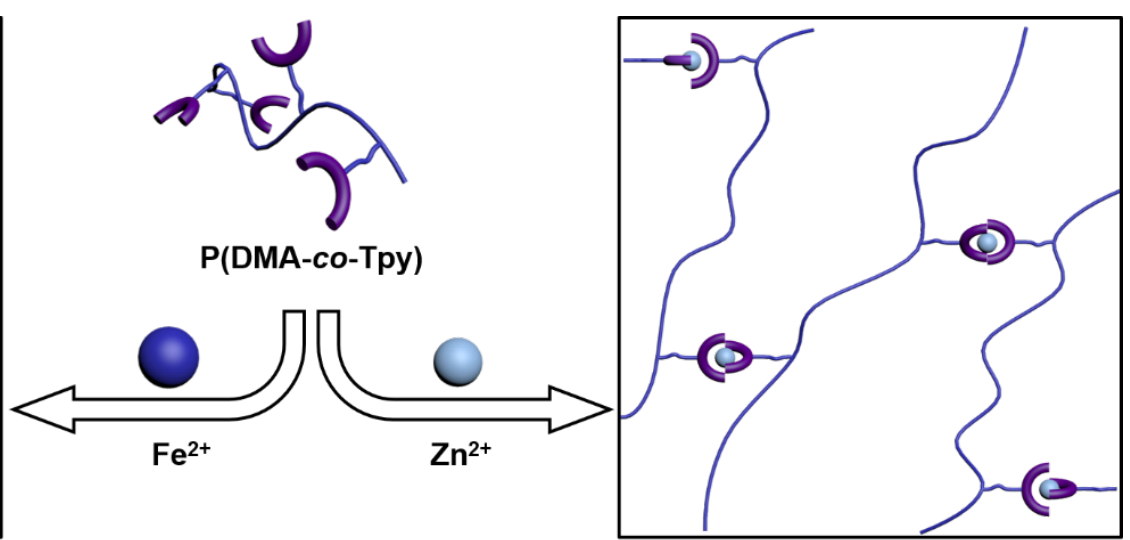

Individual $\mathrm{Zn}^{2+}$-Tpy network

Scheme S6. Preparation of individual metal-terpyridine bonding networks in water from P(DMAco-Tpy) (6 wt.\%).

Individual networks were prepared by first dissolving a given amount of P(DMA-co-Ketone) or $\mathrm{P}$ (DMA-co-Tpy) copolymer in $400 \mu \mathrm{L}$ of deionized water. The sealed reaction vials were placed at room temperature overnight until the copolymers were dissolved completely and shaken 
periodically to get homogeneous solutions. To these solutions, $100 \mu \mathrm{L}$ of a solution containing the appropriate amount of a crosslinker were added dropwise under shaking. After the crosslinker was added, the network was formed upon standing at ambient conditions for 2 days. The final concentration of the P(DMA-co-Ketone) in sample is $10 \mathrm{wt} . \%$, and the P(DMA-co-Tpy) in sample is $6 \mathrm{wt} . \%$, respectively.

Preparation of single networks

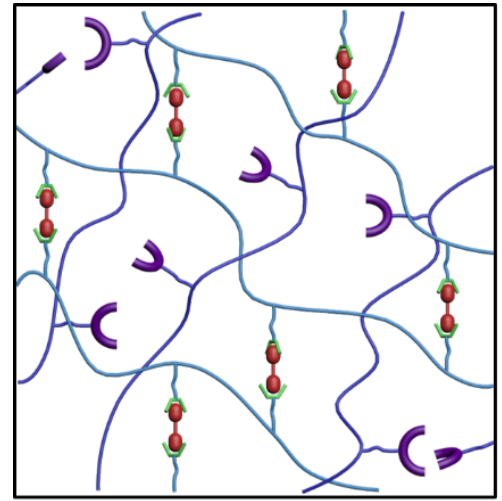

Single oxime network

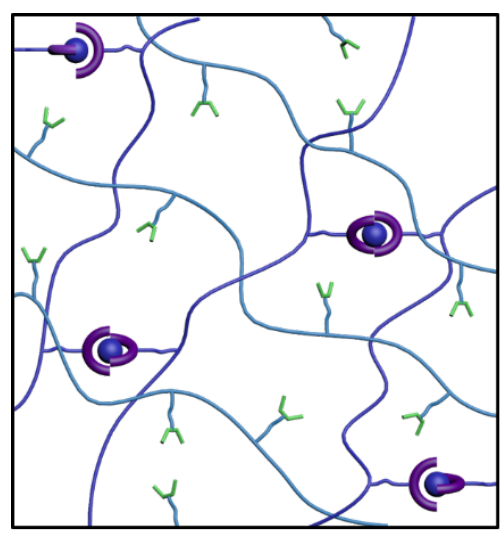

Single $\mathrm{Fe}^{2+}-\mathrm{Tpy}$ network

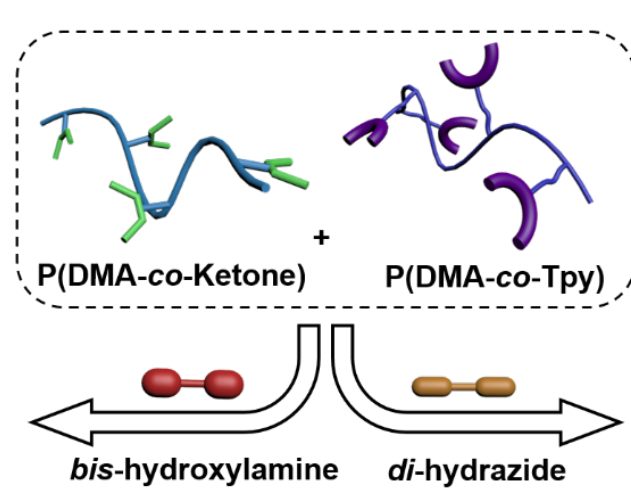

bis-hydroxylamine -hydrazide

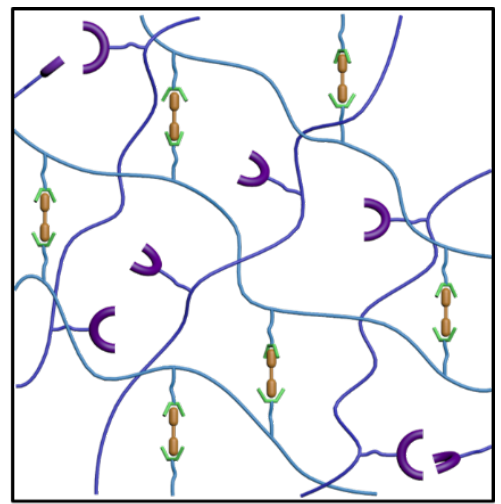

Single acylhydrazone network
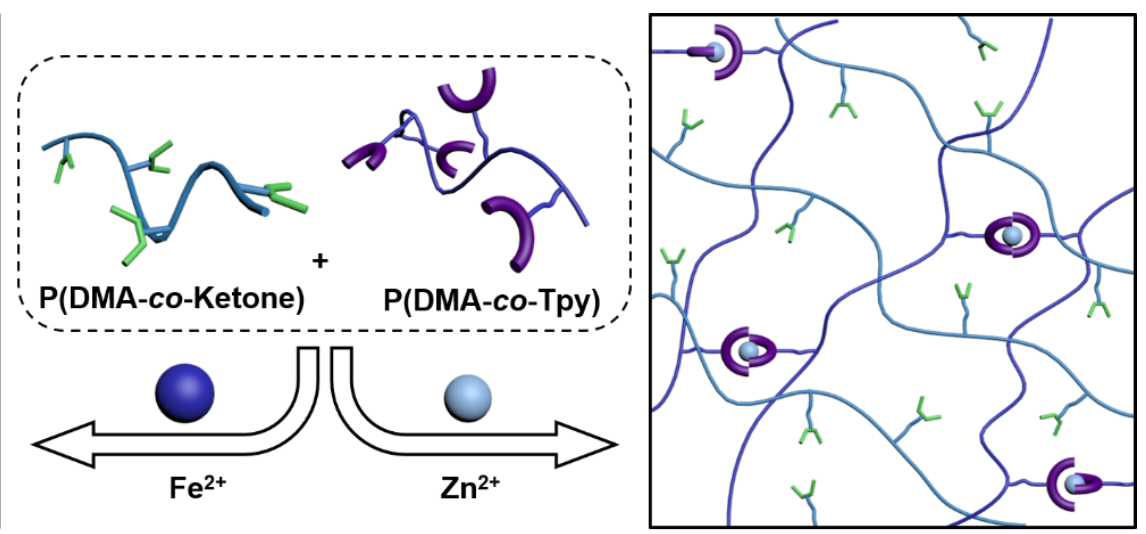

Single $\mathrm{Zn}^{2+}$-Tpy network

Scheme S7. Preparation of single networks in water from mixed copolymers (16 wt.\%) of P(DMAco-Ketone) (10 wt.\%) and P(DMA-co-Tpy) (6 wt.\%). 
$500 \mu \mathrm{L}$ of single networks were prepared at a total copolymer concentration of $16 \mathrm{wt} . \%$ (10 wt.\% of $\mathrm{P}(\mathrm{DMA}-\mathrm{co}-\mathrm{Ketone})$ and 6 wt.\% of $\mathrm{P}(\mathrm{DMA}-$-co-Tpy)). The preparation process is similar to the preparation of the individual networks. The copolymers of P(DMA-co-Ketone) and P(DMAco-Tpy) were dissolved in $400 \mu \mathrm{L}$ of deionized water to get homogeneous solutions, and $100 \mu \mathrm{L}$ of a solution containing the appropriate amount of a crosslinker were then added. After 2 days of aging, the final single networks were obtained.

\section{Preparation of interpenetrating polymer networks}

In a typical experiment, $0.05 \mathrm{~g}$ of the P(DMA-co-Ketone) and $0.03 \mathrm{~g}$ of the P(DMA-co-Tpy) copolymer were mixed together and $300 \mu \mathrm{L}$ of deionized water were added. The solution was placed at room temperature overnight and shaken periodically until the copolymers were completely dissolved. To this solution, $100 \mu \mathrm{L}$ of first crosslinker solution were added dropwise under shaking to create the first network. After $24 \mathrm{~h}$, the $100 \mu \mathrm{L}$ of second crosslinker solution were added dropwise under shaking. The desired IPN hydrogels were obtained at room temperature after 2 days of aging.

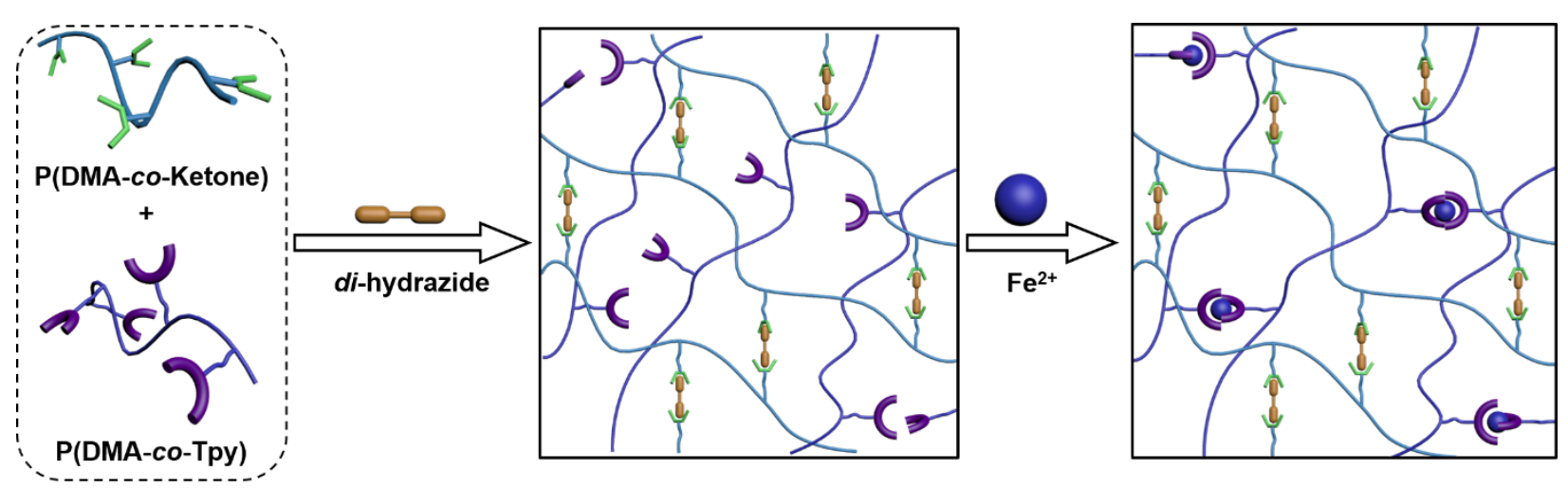

Scheme S8. Preparation of interpenetrating polymer network (IPN) hydrogels of 1Acylhydrazone $+2 \mathrm{Fe}^{2+}-\mathrm{Tpy}$. The $d i$-hydrazide is added firstly to form an acylhydrazone crosslinked 1st network, followed by adding $\mathrm{Fe}^{2+}$ to get the 2 nd network. 


\subsection{Rheological Measurements}

Rheological measurements were conducted on a rotational rheometer (MCR 301, Anton Paar) equipped with a solvent trap at a reference temperature of $25^{\circ} \mathrm{C}$. The gel samples, in the form of sheets with diameter $8 \mathrm{~mm}$ and thickness $0.2 \sim 0.4 \mathrm{~mm}$, were set in an $8 \mathrm{~mm}$ diameter parallel plate geometry. A $25 \mathrm{~mm}$ diameter parallel plate geometry with distance $0.1 \sim 0.2 \mathrm{~mm}$ was used for solution samples.

The linear viscoelastic regions of all samples were determined by oscillatory strain sweeps (0.01$1000 \%$ strain) performed at a frequency of $10 \mathrm{rad} \mathrm{s}^{-1}$. The dynamic properties of the samples were determined by oscillatory frequency sweep $\left(0.01-100 \mathrm{rad} \mathrm{s}^{-1}\right)$ at $2 \%$ strain, which is within the linear viscoelastic region.

For shear self-healing experiments, a continuous step for oscillatory time sweep (10 rad s $\left.\mathrm{s}^{-1}\right)$ was assessed with increasing strain steps switched from small strain to large strain and held for 2 min respectively. After loading a higher strain, the lower strain of $2 \%$ was applied again. 


\section{Supplementary Figures}

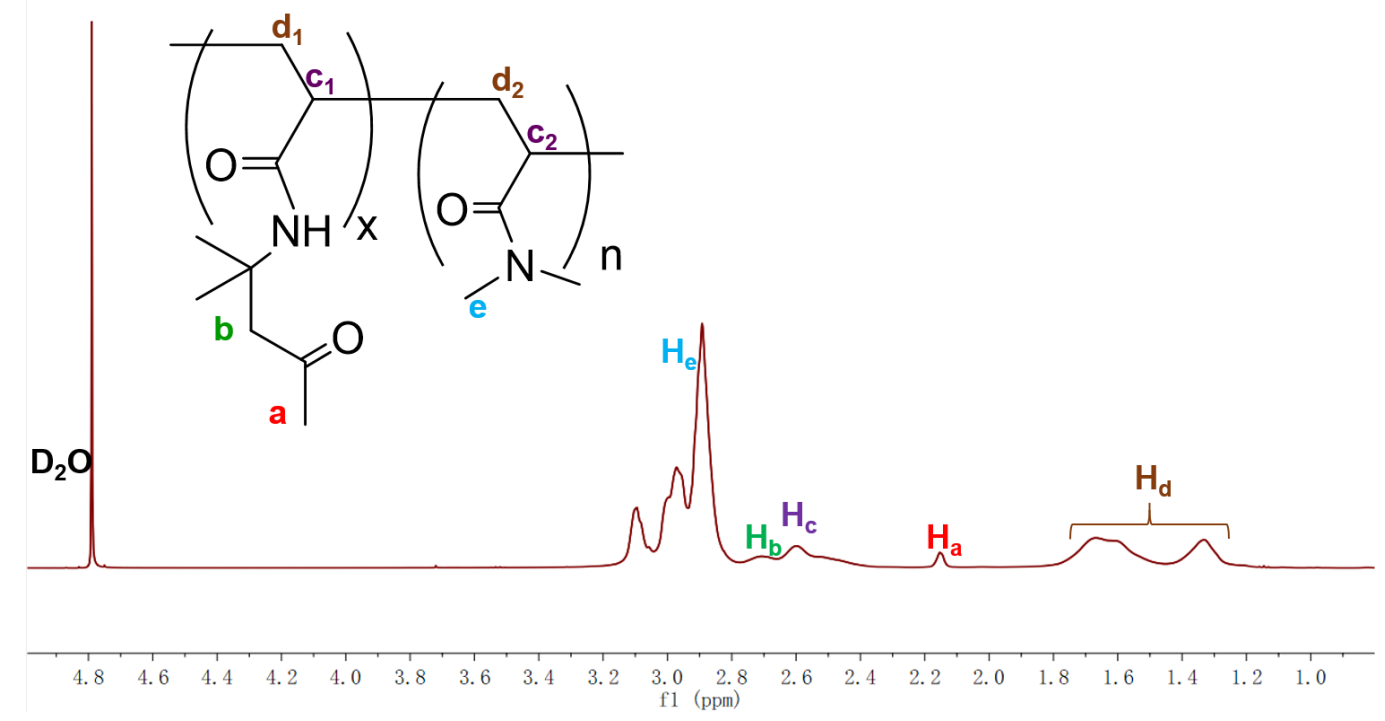

Figure S1. ${ }^{1} \mathrm{H}$ NMR spectrum of $\mathrm{P}(\mathrm{DMA}-\mathrm{co}-$ Ketone $)$.

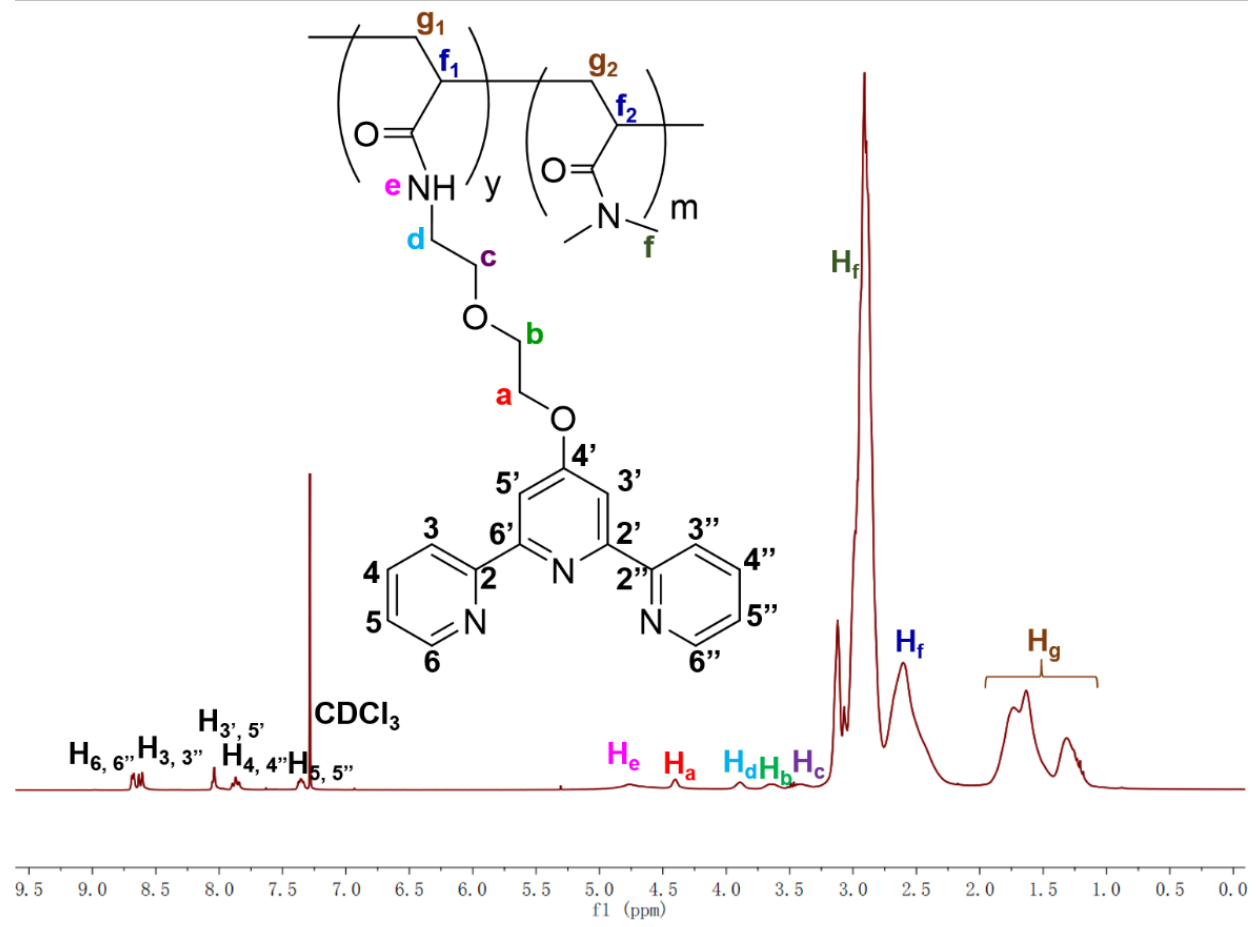

Figure S2. ${ }^{1} \mathrm{H}$ NMR spectrum of P(DMA-co-Tpy). 

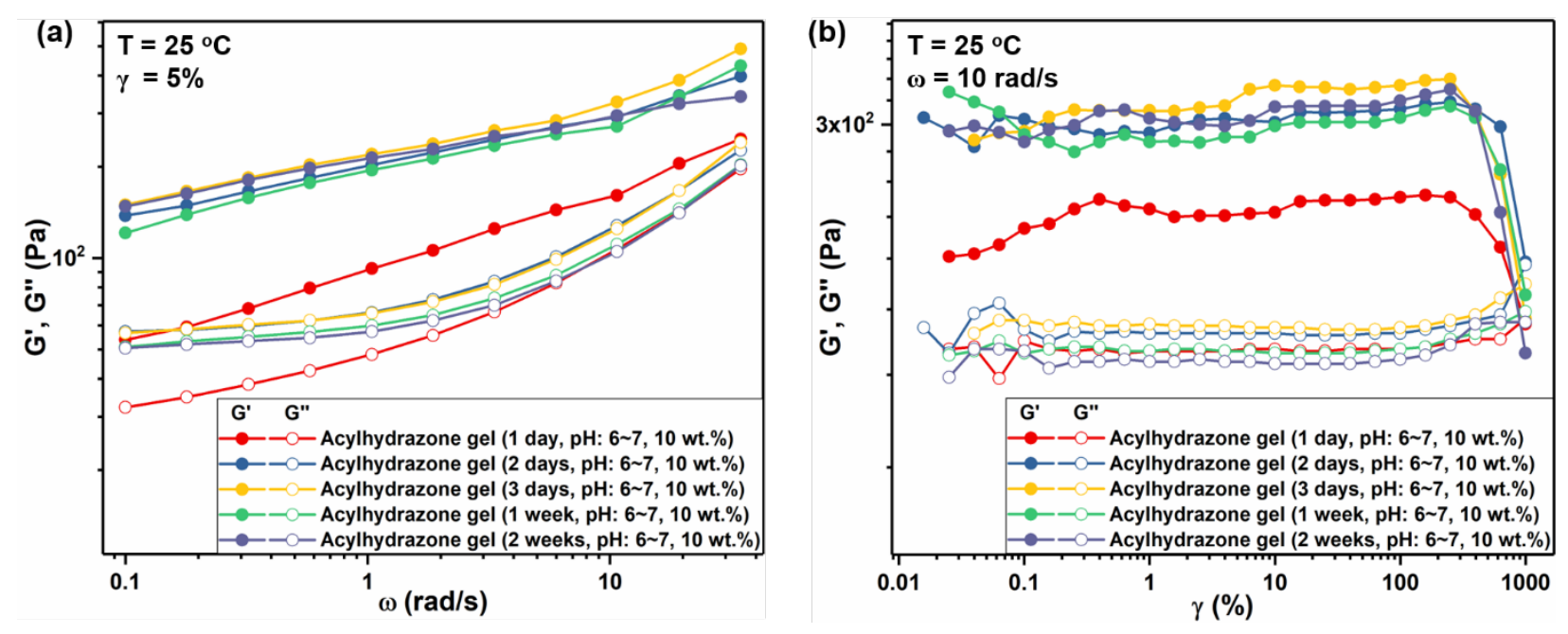

Figure S3. Oscillatory frequency sweeps (a) and strain sweeps (b) on individual acylhydrazone network hydrogel at different aging time.
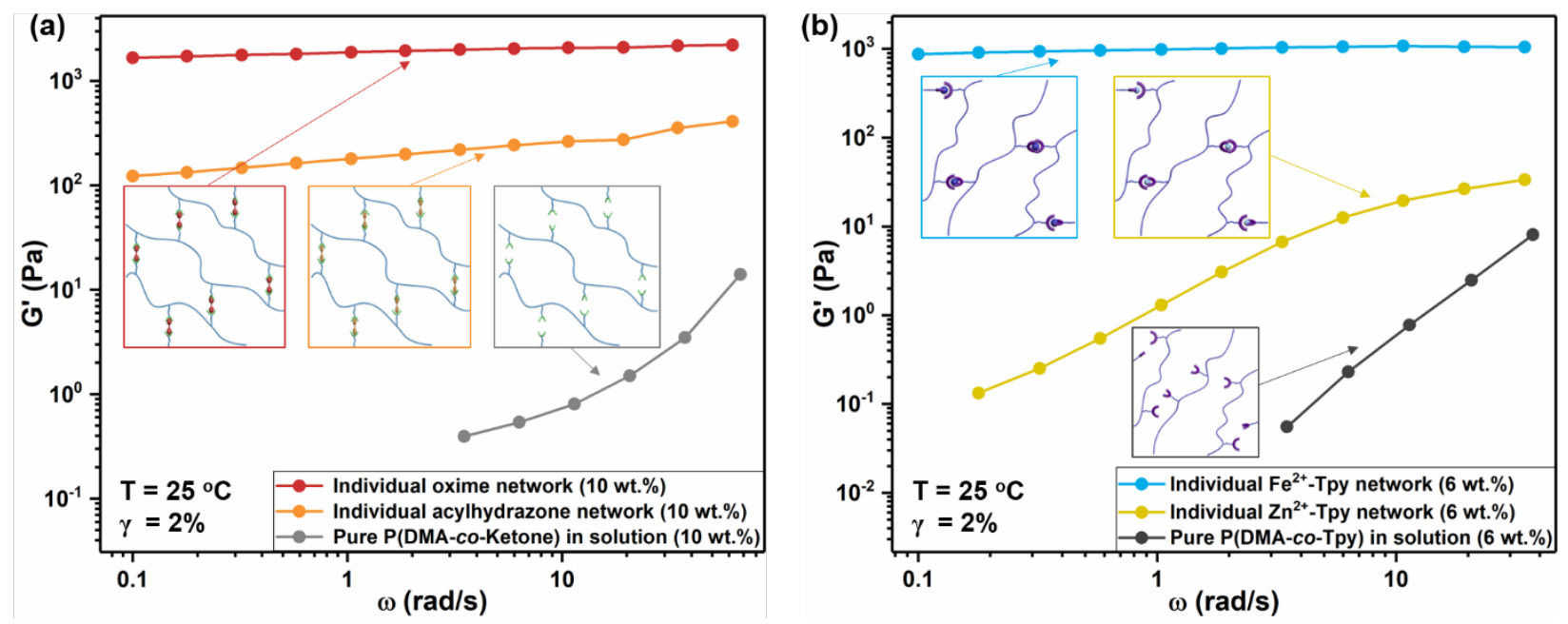

Figure S4. Oscillatory frequency sweeps on individual networks based on (a) acylhydrazone and oxime, and on (b) $\mathrm{Fe}^{2+}$-Tpy and $\mathrm{Zn}^{2+}-\mathrm{Tpy}$, compared to their respective polymer solution of $\mathrm{P}(\mathrm{DMA}-\mathrm{co}$-Ketone) and P(DMA-co-Tpy). 


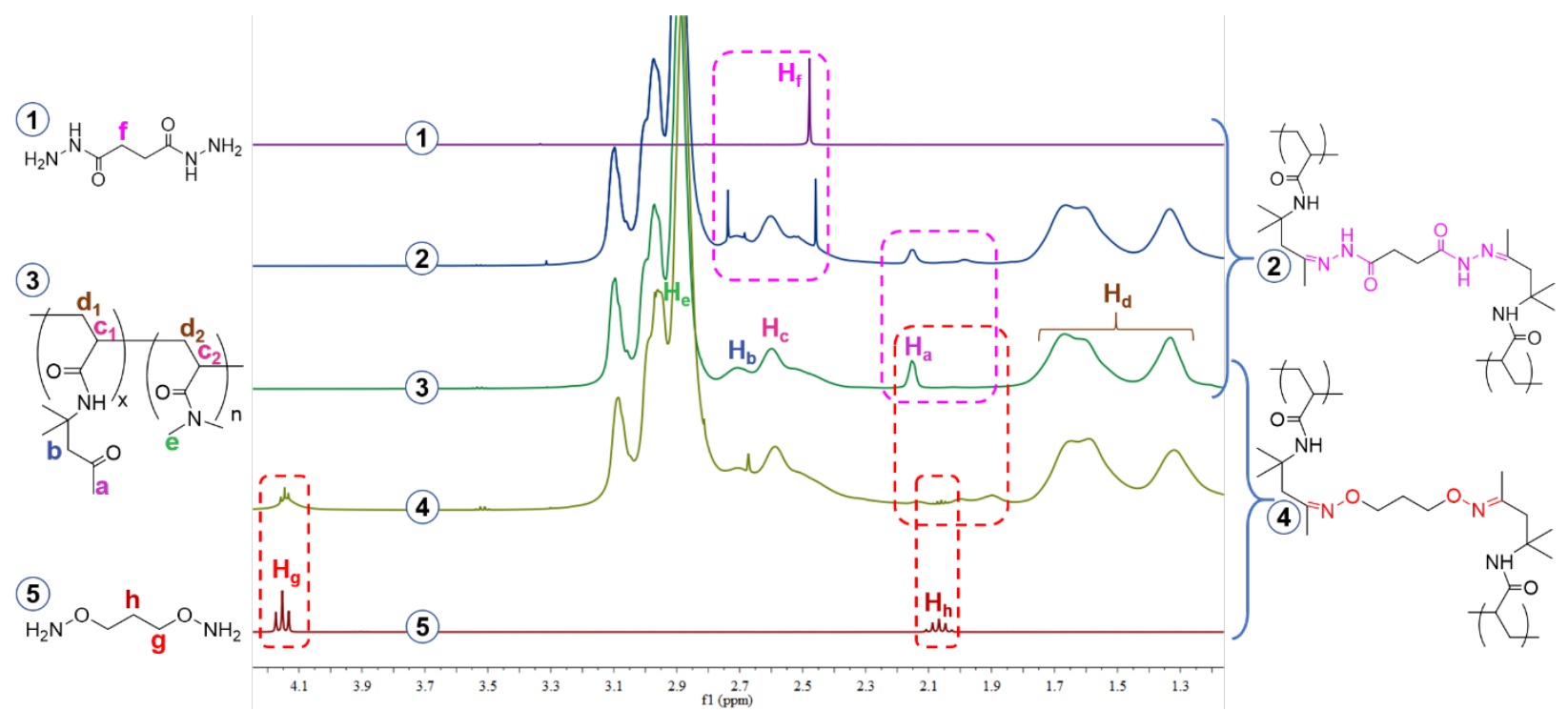

Figure S5. ${ }^{1} \mathrm{H}$ NMR spectra of $\mathrm{P}(\mathrm{DMA}-c o-K e t o n e) ~ 3$, di-hydrazide 1, bis-hydroxylamine 5, acylhydrazone network 2 and oxime network 4 in $\mathrm{D}_{2} \mathrm{O}$.

The characterizations of purified P(DMA-co-Ketone), di-hydrazide, bis-hydroxylamine, and the formed acylhydrazone network and oxime network ( 2 days of aging) were performed by ${ }^{1} \mathrm{H}$ NMR in $\mathrm{D}_{2} \mathrm{O}$ at same group concentration. As shown in Figure S5, the peak position of methyl protons adjacent to the carbonyl group of the ketone unit (signal a) has shifted from $2.15 \mathrm{ppm}$ to $1.99 \mathrm{ppm}$ for acylhydrazone network and to $1.90 \mathrm{ppm}$ for oxime network, suggesting the formation of both individual networks. For the acylhydrazone, the signal around 2,15 ppm is still visible after crosslinking, showing incomplete reaction in agreement with the rheology results (see main text). 


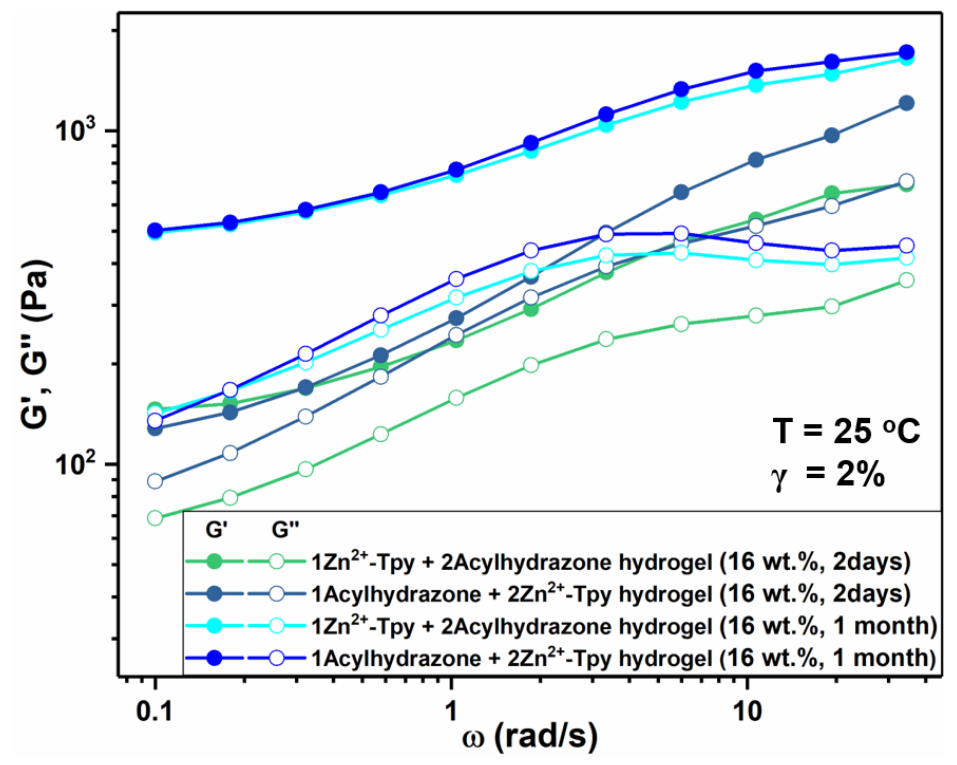

Figure S6. Oscillatory frequency sweeps on IPN hydrogels of $\mathrm{Zn}^{2+}-\mathrm{Tpy}+$ Acylhydrazone from two different preparation protocols at aging time of 2 days and 1 month, respectively.

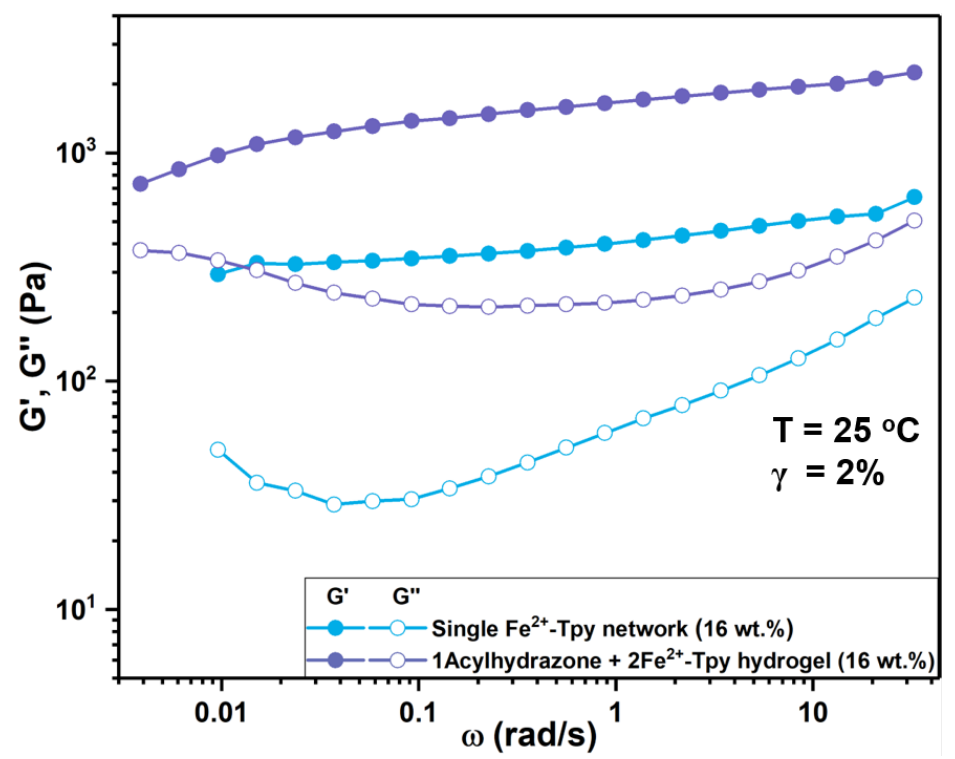

Figure S7. Oscillatory frequency sweep on the IPN hydrogel of $\mathrm{Fe}^{2+}-\mathrm{Tpy}+$ Acylhydrazone and the corresponding $\mathrm{Fe}^{2+}$-Tpy single network. 

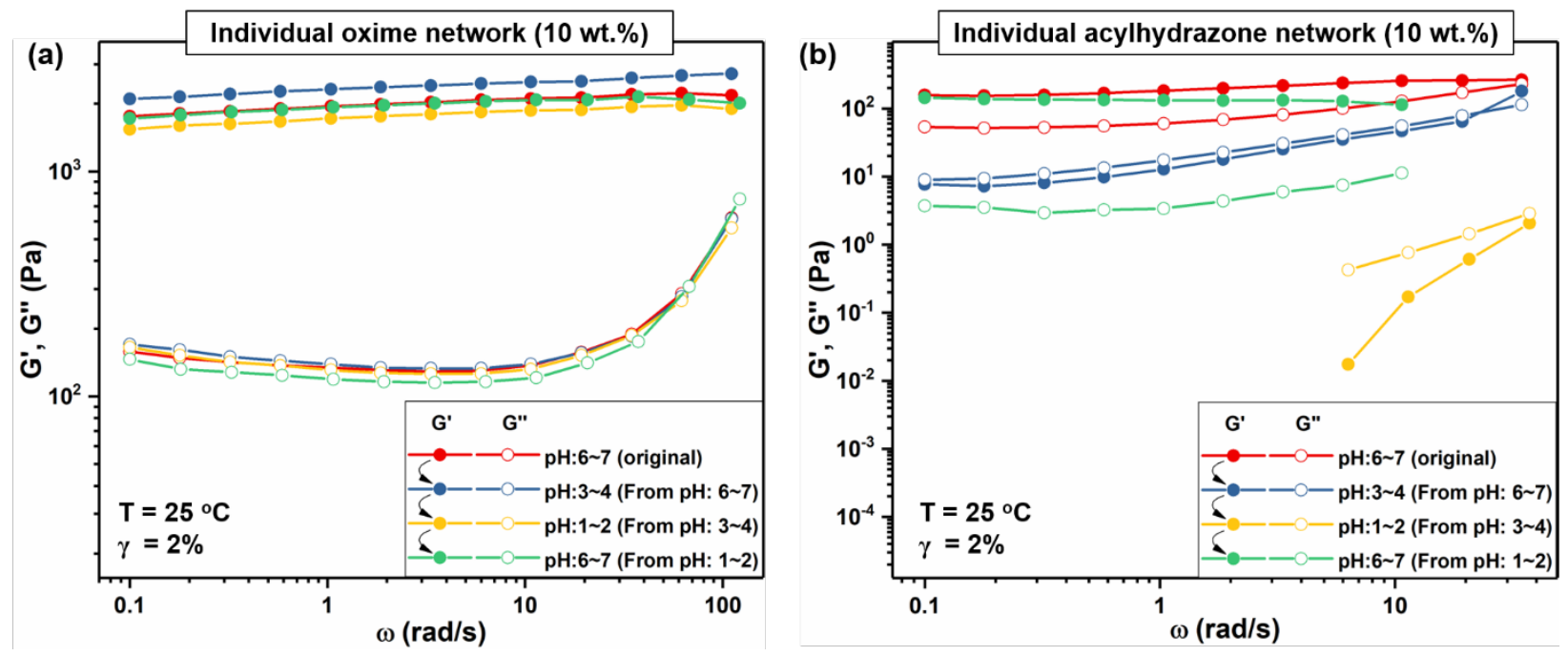

Figure S8. $\mathrm{pH}$ dependence of the dynamic moduli of individual networks of oxime and acylhydrazone. Note that the acylhydrazone sample at final pH of 6-7 (green curve, panel b) has most probably not yet reached equilibrium in view of the $G^{\prime}$ evolution at high frequency.
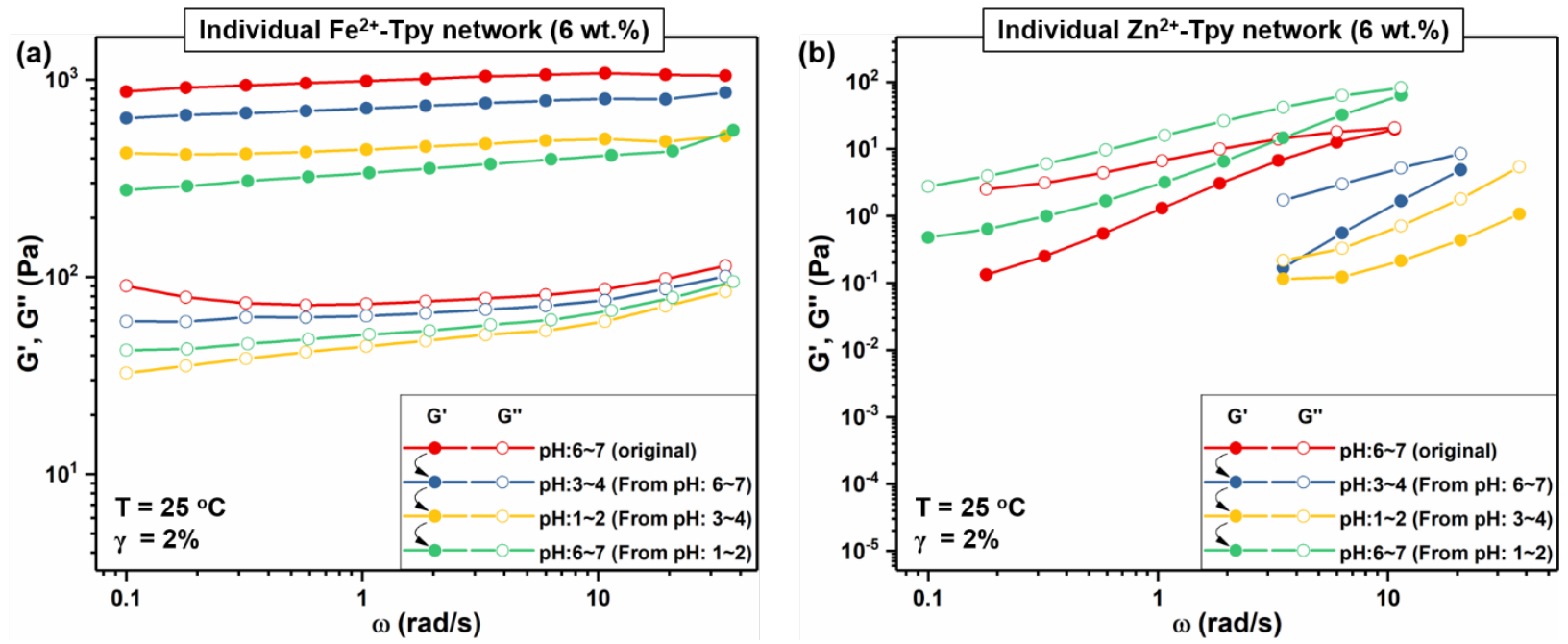

Figure S9. $\mathrm{pH}$ dependence of the dynamic moduli of individual networks of $\mathrm{Fe}^{2+}-\mathrm{Tpy}$ and $\mathrm{Zn}^{2+}$ Tpy. 


\section{References}

(1) Armarego, W. L. F.; Chai, C. L. L. Purification of laboratory chemicals, ButterworthHeinemann, 2009.

(2) Lai, J. T.; Filla, D.; Shea, R. Functional Polymers from Novel Carboxyl-Terminated Trithiocarbonates as Highly Efficient RAFT Agents. Macromolecules 2002, 35, 6754-6756.

(3) Burazerovic, S.; Gradinaru, J.; Pierron, J.; Ward, T. R. Hierarchical Self-Assembly of OneDimensional Streptavidin Bundles as a Collagen Mimetic for the Biomineralization of Calcite. Angew. Chem. Int. Ed. 2007, 46, 5510-5514. 